\title{
Reaction time measures of substance-related associations
}

Citation for published version (APA):

Houben, K. M. P. I., Wiers, R. W. H. J., \& Roefs, A. J. (2006). Reaction time measures of substancerelated associations. In R. W. Wiers, \& A. W. Stacy (Eds.), Handbook of implicit cognition and addiction (pp. 91-104). SAGE. https://doi.org/10.4135/9781412976237.N7

Document status and date:

Published: 01/01/2006

DOI:

10.4135/9781412976237.N7

Document Version:

Publisher's PDF, also known as Version of record

Document license:

Taverne

Please check the document version of this publication:

- A submitted manuscript is the version of the article upon submission and before peer-review. There can be important differences between the submitted version and the official published version of record.

People interested in the research are advised to contact the author for the final version of the publication, or visit the DOI to the publisher's website.

- The final author version and the galley proof are versions of the publication after peer review.

- The final published version features the final layout of the paper including the volume, issue and page numbers.

Link to publication

\footnotetext{
General rights rights.

- You may freely distribute the URL identifying the publication in the public portal. please follow below link for the End User Agreement:

www.umlib.nl/taverne-license

Take down policy

If you believe that this document breaches copyright please contact us at:

repository@maastrichtuniversity.nl

providing details and we will investigate your claim.
}

Copyright and moral rights for the publications made accessible in the public portal are retained by the authors and/or other copyright owners and it is a condition of accessing publications that users recognise and abide by the legal requirements associated with these

- Users may download and print one copy of any publication from the public portal for the purpose of private study or research.

- You may not further distribute the material or use it for any profit-making activity or commercial gain

If the publication is distributed under the terms of Article $25 \mathrm{fa}$ of the Dutch Copyright Act, indicated by the "Taverne" license above, 


\title{
Reaction Time
}

\section{Measures of Substance- Related Associations}

\author{
Katrijn Houben, Reinout W. Wiers, \\ AND ANNE ROEFS
}

\begin{abstract}
This chapter provides an overview of indirect RT measures of implicit associations, including the IAT, the EAST, and priming paradigms. Each indirect measure is described on a conceptual level and is illustrated with recent findings from addiction research. For each measure, a critical evaluation of its strengths and weaknesses is given including a discussion of its psychometric properties, the relativity of measured associations, its suitability for assessing ambivalence, and alternative accounts of effects found by nonassociative processes. Recent modifications, such as the Single Target IAT, the GNAT, the Modified EAST and the Single Valence EAST that have been developed in response to some of the limitations of the measures described here are also discussed.
\end{abstract}

\section{INTRODUCTION}

Addiction research is currently exploring the value of implicit measures for assessing cognitions believed to be involved in the etiology and maintenance of addictive behaviors. Traditionally, addiction-related cognitions have been examined with self-report measures that ask respondents for introspection (see Wiers et al., Chapter 22). Self-report measures, however, have been criticized because of their susceptibility to self-presentation biases and the possibility that cognitive-motivational processes mediating addiction are not accessible through conscious introspection (e.g., Nisbett \& Wilson, 1977; Stacy,

AUTHOR'S NOTE: First and second author are funded by a "VIDI" grant from the Dutch National Science Foundation (N.W.O.) awarded to the second author. The authors wish to thank Jan De Houwer, Martin Zack, Alan W. Stacy, and Tibor P. Palfai for helpful comments on the first draft of the manuscript. Correspondence concerning this chapter can be addressed to Katrijn Houben, Experimental Psychology; Uns 40; Maastricht University; PO BOX 616; 6200 MD Maastricht, The Netherlands. E-mail: K.Houben@psychology.unimaas.nl 
1997). These two key problems of self-report measures have encouraged researchers to develop implicit measures that assess cognitions indirectly from behavior such as reaction time (RT).

Despite the increased use and popularity of implicit measures, the denotation of the term "implicit" remains confusing. Some have argued that the term refers to the measurement procedure (Fazio \& Olson, 2003), whereas others believe that implicit measures have privileged access to automatically activated cognitions and tap different underlying processes than self-report measures (e.g., Cunningham et al., 2001; Stacy, 1997; Wilson et al., 2000). According to De Houwer (Chapter 2), these two views of implicit measures actually refer to different things, namely to the measurement procedure and the outcome of the measurement procedure, respectively. Following De Houwer, the terms "indirect" and "direct" are used here to denote measurement procedures, whereas the term "implicit" is used for cognitions assessed with indirect measures.

This chapter discusses the merits of a subset of indirect measures, namely indirect RT-based association measures. Several RT association measures, including the Implicit Association Test (IAT; Greenwald et al., 1998), the Extrinsic Affective Simon Task (EAST; De Houwer, 2003), and priming paradigms are described conceptually and illustrated with examples from addiction research. A critical review of strengths and weaknesses is given for each measure and recently developed modifications are discussed. For an extended overview of indirect measurement procedures see Wiers et al. (2004).

\section{THE IMPLICIT ASSOCIATION TEST}

The IAT (Greenwald et al., 1998) is a double categorization task that requires the classification of stimuli into four different categories with two response keys. Typically, two categories represent the target concepts (e.g., alcohol vs. soft drinks) and two categories correspond to the poles of an attribute dimension (e.g., positive vs. negative). During the critical trials of the IAT, the target and attribute categories are assigned to two response keys in two different combinations. During one combination task, for example, participants have to classify both alcohol and negative words with one response key and soft drinks and positive words with the other. During the reversed combination task, alcohol and positive are assigned to the same key and soft drinks and negative to the other. Because performance will be better when concepts that are associated in memory are classified with the same response key (compatible), than when concepts sharing a response key are not or only weakly associated (incompatible), one of these combinations typically leads to faster and more accurate performance compared with the other. This performance difference is referred to as the IAT effect and is assumed to reflect the strength of implicit associations between the target and attribute categories (Greenwald et al., 1998).

\section{Application to Addictive Behaviors}

The IAT has already been used in numerous studies examining substance-related cognitions. For example, Swanson et al. (2001) and Huijding et al. (2005) compared smokers and nonsmokers' implicit smoking associations with valence. In both studies, both smokers and nonsmokers were found to have stronger negative implicit smoking associations compared with a number of different contrast categories such as sweets, exercise, and writing. Likewise, Field et al. (2004) used the IAT to examine cannabis users and nonusers' implicit cannabis associations compared with features of the natural environment. Nonusers showed stronger 
negative implicit cannabis associations compared to cannabis users. Wiers et al. (2002) measured heavy and light drinkers' implicit alcohol associations with the IAT in two dimensions: valence and arousal. Both heavy and light drinkers implicitly associated alcohol with negative valence compared with soft drinks, whereas only heavy drinkers demonstrated alcohol-arousal associations. These findings have been replicated in a sample of heavy drinkers (Wiers et al., 2005 ) and in a sample of patient drinkers (De Houwer et al., 2004). Palfai and Ostafin (2003a) recently modified the IAT by replacing the valence categories with approach and avoidance attributes. Results demonstrated that alcohol is associated with approach motivations (or action tendencies) in hazardous drinkers. Further, stronger alcoholapproach associations significantly correlated with urge to drink and arousal-reactivity in anticipation of alcohol consumption. Both the implicit arousal and the approach associations in heavy drinkers have been linked to the incentive-sensitization theory (Robinson \& Berridge, 1993, 2003; see also Wiers et al., Chapter 22), which states that activation of a sensitized "wanting" system automatically increases attention, arousal, and approach responses, in the absence of "liking." Moreover, these findings underscore the usefulness of assessing substance-related associations in other dimensions than valence alone (e.g., arousal-sedation, approach-avoid), as has been demonstrated in other areas of psychopathology (e.g., Teachman et al., 2001; Teachman \& Woody, 2003). Furthermore, the IAT can also be used with pictorial instead of verbal stimuli and has been shown to be robust against influence from such stimulusrelated variations (Hofmann et al., 2004). To illustrate, Swanson et al. (2001) contrasted smoking pictures with nonsmoking pictures in an IAT and found both smokers and nonsmokers to have an implicit preference for nonsmoking pictures.

\section{Strengths and Weaknesses}

The IAT shows good internal consistency, in the region of .80 . Stability over time is typically lower with an average test-retest value of .60 (e.g., Bosson et al., 2000; Cunningham et al., 2001; Greenwald \& Nosek, 2001; around .70 for the alcohol IAT; Wiers et al., 2005). Promising results were also found regarding the convergent validity of the IAT (Cunningham et al., 2001; Greenwald \& Nosek, 2001), though most studies have found correlations between indirect measures to be inconsistent, weak, and/or nonexistent (e.g., Bosson et al., 2000; Olson \& Fazio, 2003). A large range of positive correlations between the IAT and direct measures have been found with a low but positive average of .24 (Hofmann et al., 2004).

The IAT, however, is not without limitations and recent research has uncovered problems that may compromise the interpretation of IAT effects. First, it is unclear which associations are assessed with the IAT. The IAT primarily measures associations between concepts at category level rather than at the level of individual exemplars (De Houwer, 2001, 2002). Exemplars can influence IAT effects by determining the target category context or supporting a category re-definition (Govan \& Williams, 2004; Mitchell et al., 2003), but ultimately the categories determine IAT effects. This implies that category labels are important and that the IAT is vulnerable to influences of label associations (i.e., the "label effect"). In addition, IAT effects appear to be susceptible to contamination by culturally shared associative knowledge that is not necessarily personally endorsed (Karpinski \& Hilton, 2001; Olson \& Fazio, 2004).

Second, the IAT only provides a measure of the relative strength of implicit associations because the IAT requires two categories and two attribute categories (De Houwer, 2002). The bipolarity of the target dimension 
carries the implication that the IAT measures the strength of the association between one target concept and the attributes relative to the contrast target category. Therefore, conclusions about implicit associations of a single target category are unwarranted because the possibility always exists that the contrast category influenced IAT effects. Moreover, the bipolarity of the attribute categories prevents assessment of ambivalence, because it is impossible to find associations between a target category and both poles of the attribute dimension. This may be especially problematic for addictive behaviors, where ambivalence is typically quite strong (Conner \& Sparks, 2002) and even at the core of some of its definitions (e.g., Orford, 2001).

Third, IAT effects are assumed to reflect the strength of implicit associations in memory (Greenwald et al., 1998) and, according to the analysis of De Houwer (2001), stimulusresponse compatibility effects underlie IAT effects. Presumably, compatibility between the short-term associations of the response keys created by instructions and the intrinsic, longterm associations of the stimuli facilitates performance. Because IAT effects are based on the comparison of performance between two tasks, however, nonassociative processes can also influence IAT effects. Such an account of IAT effects is provided by Rothermund and Wentura (2001, 2004). They propose that salience or figure-ground asymmetries can cause IAT effects, independent of implicit associations. When one of the categories of an IAT dimension is more salient than the other, the most salient category will attract attention. This salient category becomes the so-called figure, whereas the other category constitutes the (back)ground. Subsequently, when both the target and attribute figure are mapped onto the same response, performance will be better compared with when one figure and one ground category are assigned to the same response. Similarly, the task-switching account (Mierke \& Klauer, 2001, 2003) also explains part of the IAT effects in terms of nonassociative processes: the IAT involves a switch between two different tasks (typically an easy and a difficult combination) and IAT effects are larger for people who have difficulties with task-switching, irrespective of their associations. This task-switching is thought to involve executive control processes and comes with a performance cost, causing slower and less accurate responding. This aspect of the IAT measurement procedure may be particularly worrying for comparisons of groups that differ in their task-switching abilities, such as young versus older or addicted versus nonaddicted participants.

\section{Recent Developments}

\section{IAT Developments}

Jajodia and Earleywine (2003) modified the IAT by eliminating attribute bipolarity to enable assessment of ambivalence toward alcohol. Attribute categories were presented in a unipolar format, by contrasting both positive and negative attributes with attribute categories made up of unrelated neutral words (e.g., basic, intermediate). Results showed implicit alcohol associations with both positive and negative valence relative to mammals, implying that implicit alcohol attitudes are in fact ambivalent. Furthermore, Houben and Wiers (2004) examined the extent to which the label effect, target and attribute bipolarity, and figure-ground asymmetries influence findings with alcohol IATs. In a first study, the influence of using the label "alcohol" versus the label "beer" was examined as well as the effect of using the contrast category "animals" instead of "soft drinks." Moreover, attribute bipolarity was eliminated by testing positive, negative, arousal, and sedation attributes relative to (different) neutral attribute categories. Results showed only minor effects of the labels and contrast categories and both alcohol 
and beer were very strongly associated with negative affect, strongly with positive affect and arousal, and moderately with sedation. These findings provide additional support for the existence of ambivalent implicit alcohol associations and underscore the need to assess implicit alcohol associations in a unipolar format with respect to the attributes. In a second study, participants performed visual search tasks (Rothermund \& Wentura, 2004) to examine figure-ground asymmetries between categories that made up an IAT dimension in the first study. Results showed that the neutral categories were more salient than the positive, negative, and sedation categories, but showed no figure-ground asymmetries for the target dimensions or for the arousalneutral dimension, suggesting that figureground effects cannot explain the IAT results of the first study.

According to Olson and Fazio (2004), some IAT properties might promote the use of extrapersonal (cultural) associations (cf. Karpinski \& Hilton, 2001) by increasing the accessibility of normative information. Therefore, they introduced the personalized IAT (see also Fadardi et al., Chapter 9), which reduces this contamination by extrapersonal associations. First, it eliminates normative implications associated with the labels "positive" and "negative" through the use of the labels "I like" and "I dislike." Second, it uses attribute stimuli that are not normatively associated with valence but that have little evaluative consensus (large variability) while still being attitude-evoking (e.g., football, coffee). Finally, no error feedback is given to participants to avoid suggesting that there is a normative correct response. The personalized IAT was found to reveal less racial prejudice and was more strongly correlated with direct measures, suggesting a reduced influence of extrapersonal associations (Olson \& Fazio, 2004). Nosek and Hansen (2004), in contrast, argue that the original and the personalized IAT both capture unique attitude-relevant aspects, reflecting the multidimensionality of attitudes. In a series of studies, evidence for the multidimensionality of attitudes was found and results suggested that both IAT versions were capturing different aspects of these attitude constructs.

\section{IAT Variants}

Wigboldus et al. (2004) developed the Single Target IAT (ST-IAT), which is structurally similar to the IAT, with the difference that only one target category is used. Participants are instructed to classify both this target and one attribute category (e.g., alcohol and negative) with one response key and the other attribute category (e.g., positive) with the second response key. Unlike the IAT, the ST-IAT measures associations between only one target concept and the attributes without a second contrasting target category.

The GNAT (Go/No-Go Association Task; Nosek \& Banaji, 2001) is another IAT variant designed to assess associations between a single target category and two poles of an attribute dimension. In this task, participants press one response key for targets and attributes (Go) and are instructed to ignore other stimuli (No-Go). The strength of associations is assessed by determining the extent to which stimuli belonging to the target category and one pole of the attribute dimension can be discriminated from distracter stimuli. As it is in the case of the ST-IAT, the target is first paired with one pole of the attribute dimension and subsequently with the other in two combination tasks. Differences in sensitivity between these two combinations reflect the association between the target and the attributes (Nosek \& Banaji, 2001). One major advantage of the GNAT is that the task is very flexible with respect to the choice of the distracter set, allowing assessment of single associations with a target category (Nosek \& Banaji, 2001). Dabbs et al. (2003) 
used a portable version of the GNAT to assess smokers and nonsmokers' smoking attitudes. Preliminary results showed smokers to have a more favorable implicit attitude toward smoking compared with nonsmokers.

Both the ST-IAT and the GNAT are unipolar with respect to the target category and offer a way to assess associations with targets that do not have a natural opposing contrast, such as smoking. Both IAT variants, however, compare performance between two tasks, making nonassociative alternative accounts of effects possible. Also, since categories are labeled in both tasks, label effects may still influence results. Finally, attribute bipolarity remains a problem for both tasks when assessing associations that are possibly ambivalent.

\section{THE EXTRINSIC AFFECTIVE SIMON TASK}

The EAST (De Houwer, 2003) is a categorization task that allows measurement of single target associations within one task. In the EAST, attribute words (e.g., positive and negative) are typically classified by meaning with two response keys. Because of these task instructions, the response keys become extrinsically associated with the meaning of the attributes assigned to them, creating, for example, an extrinsically positive and an extrinsically negative response key. In contrast, target words (e.g., alcohol, soda) are classified with respect to an irrelevant stimulus property (e.g., color, shape) with the same two response keys. Participants, for example, may be instructed to respond with one key to positive words and to alcohol and soda stimuli that are presented in blue and to respond with the other key to negative words and to alcohol or soda targets that are presented in green. Subsequently, implicit associations between alcohol and valence are defined as the performance difference between giving an extrinsically positive response to a (blue) alcohol target and giving an extrinsically negative response to a (green) alcohol target.

\section{Application to Addictive Behaviors}

In a recent study, De Houwer et al. (2004) assessed implicit alcohol associations with an EAST in a sample of patients. Alcoholics were more accurate in responding to soft drink stimuli with an extrinsically positive response than with an extrinsically negative response, but showed no performance difference for alcohol stimuli. These results suggest that participants had a favorable attitude toward soft drinks and a neutral or ambivalent attitude toward alcohol. Wiers et al. (2003) assessed implicit alcohol associations with a valence-EAST and an arousalEAST in drinking students and found that participants held implicit alcohol-arousal associations, replicating IAT findings (e.g., Wiers et al., 2002).

\section{Strengths and Weaknesses}

Until now, few studies have examined the reliability and validity of the EAST, although promising results have been obtained when assessing attitudes for which meaningful interindividual differences exist (De Houwer, 2003). Typically, EAST effect sizes are somewhat smaller than IAT effect sizes (De Houwer, 2003). Unlike the IAT, EAST effects are based on comparison of performance within one task, which makes nonassociative accounts of EAST effects (e.g., salience asymmetries, task-switching) less likely. Also, the EAST allows assessment of single associations between one target and the attributes, even when multiple target categories are used. Not only are target dimensions presented in a unipolar format, they are also presented without labels, making label effects less likely. The attribute dimension, however, is still presented in a bipolar 
format, making the EAST, like the IAT, unsuitable to assess ambivalent associations.

\section{Recent Developments}

Wiers, et al. (2003) tested a ModifiedEAST (M-EAST) for assessing multiple and ambivalent alcohol associations within one task. The M-EAST is structurally similar to the EAST, with the modification that target words now have to be classified by meaning and attributes by an irrelevant property. The M-EAST has the advantage that attribute dimensions are no longer bipolar. Because the targets are now bipolar again, however, only relative associations can be assessed. Using the M-EAST, Wiers et al. (2003) created an extrinsic alcohol and an extrinsic soft drink response key while positive, negative, arousal, and sedation attributes were presented in blue and green. Performance of heavy-drinking men was found to be better when making an extrinsically alcohol-related response compared to an extrinsically soft drink-related response to both arousal and sedation attributes. These results demonstrate implicit alcohol associations with both arousal and sedation. No reliable performance differences were found for positive and negative attributes.

De Liver et al. (2003) developed the Single Valence-EAST (SV-EAST) to enable the assessment of ambivalent attitudes. The SV-EAST is structurally similar to the EAST with attributes being classified by meaning and targets by an irrelevant property. Unlike the EAST, however, only one classification response is used (as in the GNAT). For example, attribute words require a response when they possess valence whereas attributes without valence have to be ignored. During one block, only positive and neutral attributes are presented or only negative and neutral attributes. Ambivalent (e.g., alcohol) and neutral targets are presented that require a classification response when presented in blue but have to be ignored when presented in green. The assumption is that responding to ambivalent targets will be superior compared with responding to neutral targets. The SV-EAST has the advantage that it presents both the target and attribute dimension in a unipolar format and without category labels.

\section{PRIMING MEASURES}

Sequential priming techniques are particularly useful for studying the associative structure of memory representations (Bargh \& Chartrand, 2000). In semantic priming, associations are assessed between two different concepts and in affective priming, associations are assessed between a concept and its evaluation.

In semantic priming procedures, the presentation of a prime word or phrase, assumed to provide a semantic context, is followed by the presentation of a target word to which a response has to be generated. This response typically involves pronunciation of the target word (pronunciation task) or a word/nonword decision (lexical decision task). Targets can be semantically related or unrelated to the prime, and priming effects are demonstrated when response latencies or the percentage of errors for targets following unrelated primes are larger than for targets following a related prime (Bargh \& Chartrand, 2000; Neely, 1991).

Affective or evaluative priming techniques involve the presentation of a prime that is evaluatively consistent or inconsistent with a subsequently presented target. The presentation of an attitude object as a prime is thought to activate any associated evaluations and hence facilitate the processing of and responding to evaluative consistent targets (Fazio, 2001; Klauer, 1998; Klauer \& Musch, 2003). Most often, participants are asked to decide whether the target is "good" or "bad" (evaluative categorization task); 
however, affective priming effects have also been found with the lexical decision task (e.g., Wentura, 2000) and the pronunciation task (under certain conditions; e.g., Hermans et al., 1994, 2001; Spruyt et al., 2002).

For both semantic and affective priming procedures, priming effects are indicated by an interaction between prime and target valence or meaning, showing faster performance when prime and target are congruent than when they are incongruent. Several accounts of priming effects have been proposed, including spreading activation (Fazio et al., 1986), response competition/facilitation (Klinger et al., 2000), affective-matching (Klauer, 1998; Klauer \& Musch, 2003), and compound cue theory (Ratcliff \& McKoon, 1988), but also more controlled processes like target expectancies (Neely, 1991).

\section{Application to Addictive Behaviors}

Using a semantic priming task, Hill and Paynter (1992) demonstrated faster responding to alcohol targets that were preceded by alcohol-related primes than to alcohol targets that were preceded by unrelated primes for alcohol-dependent drinkers. No such priming effect was found for the nondependent drinkers. Moreover, Weingardt et al. (1996) examined the association between alcohol and outcome states using a semantic priming task and were able to show that the presentation of positive outcomes of drinking alcohol facilitated the naming of subsequent alcohol-related words. Furthermore, results showed that more drinking experiences were accompanied by an increased priming effect. Zack and colleagues used semantic priming to assess associations between possible antecedents of drinking and alcohol. In line with this idea, Zack et al. (1999) showed that problem drinkers with high psychiatric distress displayed significant activation of alcohol concepts by negative affective primes. The opposite was also found in these problem drinkers: Negative concepts were primed by alcohol primes. Problem drinkers with low psychiatric distress showed inhibition in both these conditions. Zack et al. (2003) examined the association between alcohol and antecedent mood states and demonstrated faster pronunciation of alcohol targets following negative mood phrases in young drinkers with high- and low-anxiety sensitivity.

Palfai and Ostafin (2003b) used an affective priming task to examine the influence of alcohol consumption on the activation of alcohol outcome expectancies. Results indicated that, regardless of whether expectancy words were preceded by a neutral or an alcohol prime, participants responded faster to positive expectancies after consuming alcohol than after consuming a placebo beverage. Apparently, alcohol consumption increased the activation of positive expectancies but not associative memory links between alcohol and expectancies. Ostafin et al. (2003) modified the affective priming task by replacing positive and negative target words with targets related to approach and avoidance behavior. Results showed that alcohol-binge episodes and alcohol-related problems were correlated with weak associations between alcohol and avoidance tendencies, however, not with strong associations between alcohol and approach tendencies (see also Wiers et al., Chapter 22).

\section{Strengths and Weaknesses}

Priming has been proven to be useful, but effect sizes are typically small and reliability of individual differences is typically low (e.g., Bosson et al., 2000) to moderate (e.g., Cunningham et al., 2001). Priming measures are, however, only explained in terms of associative relationships and priming effects necessitate no comparison of different sets of words since the same stimulus words are used to make up both the congruent and the 
incongruent prime-target pairs. This avoids uncontrollable influences on priming effects such as effects of familiarity and salience (Klauer, 1998).

\section{OTHER INDIRECT RT ASSOCIATION MEASURES}

We will now briefly discuss two other measures that have been used in addiction research. A full review of these measures is unfeasible because of limited space and therefore, only the main task properties will be described for these measures and only some points of criticism will be given. First, the primed emotional Stroop task can be used to assess implicit associations by examining color-naming latencies for target words that are preceded by prime words. Participants are instructed to ignore the meaning of target words and only name the color of the words. Unlike in other indirect association measures, implicit associations are indicated in the primed emotional Stroop task by slower performance on trials where target words are preceded by a congruent prime. Both Kramer and Goldman (2003) and Stewart et al. (2002) have recently used the primed emotional Stroop to examine alcohol-related associations. In both studies, however, primes were presented for an unusually long period (2 seconds, stimulus onset asynchrony $(\mathrm{SOA})=5$ seconds and $500 \mathrm{~ms}, \mathrm{SOA}=1300 \mathrm{~ms}$, respectively) when compared with priming studies where priming effects have been found to dissipate at SOAs longer than $300 \mathrm{~ms}$ (e.g., Hermans et al., 2003). This makes the indirect nature of the test somewhat questionable.

Second, accessibility measures provide another way for measuring implicit associations. For example, participants can be instructed to respond to a series of expectancy words that are preceded by a prompt (e.g., "Alcohol makes me") by pressing one of two response keys (yes or no). The accessibility of expectancies is assessed by examining the time necessary to endorse expectancy items (e.g., Palfai, 2002; Palfai et al., 1997; Palfai et al., 2000). These accessibility measures are probably the closest to the direct self-report measures of all measures reviewed here, because they ask respondents to self-report on their cognitions while the accessibility of these cognitions is indirectly determined from response times.

\section{DISCUSSION}

Assessment of substance-related cognitions with indirect measures has provided new insights into the cognitions involved in addictive behaviors. There are at least two reasons for supplementing traditional direct selfreport measures with indirect measures: selfpresentation biases and limited cognitive accessibility. In this chapter, an overview was provided of indirect RT measures of implicit associations. When comparing these measures, it is obvious that the largest effects can be obtained with the IAT. Several problems have been attributed to this test, however, and IAT effects can be explained by both associative and nonassociative accounts. Therefore, IAT effects probably do not only reflect implicit associations in memory, but also reflect artifacts of the measurement procedure. In response to these problems, several other indirect association measures have been developed, such as the ST-IAT, the EAST, and the GNAT, which overcome some, but not all of the problems associated with the IAT measurement procedure. Priming procedures, on the other hand, appear to be less susceptible to nonassociative factors. Accounts of priming effects are primarily in terms of semantic or affective relationships between concepts and none explain priming effects in terms of artifacts of the measurement procedure. Typically, priming effects are also smaller than, for example, IAT 
effects, possibly because effects are not enlarged by nonassociative effects and reflect only the associations of interest.

One general limitation that applies to most indirect measures reviewed here is that these measures do not fully capture the directionality of implicit associations. Because targets typically both precede and follow attributes, an association between alcohol and an attribute can reflect both an association with an expected outcome (e.g., alcoholpositive: Drinking alcohol causes a positive mood) or with an antecedent (e.g., positivealcohol: When in a positive mood, one should drink alcohol). This temporal sequence of associations is not addressed by current RTbased indirect measures. For example, it remains puzzling that people continue to use addictive substances while IAT research continues to find evidence that these substances are implicitly associated with negative valence. One possible explanation is that associations with addictive substances are typically ambivalent and this conclusion seems to be supported by recent research. Alternatively, it is possible that negative stimuli act as a cue for using addictive substances while addictive substances activate positive expectancies (see Wiers et al., Chapter 22). This directionality issue as well as the meaning of implicit negative substance associations should be addressed by future research on implicit drug associations.

We hope this review of RT measures of implicit associations will stimulate further research on the processes underlying the effects of these measures. We trust this will lead to further improvements of indirect association measures that can be applied in addiction research as a supplement to direct self-report measures. Ultimately, such an approach could lead to a better understanding of automatic processes in addictive behaviors and their treatment.

\section{REFERENCES}

Bargh, J. A., \& Chartrand, T. L. (2000). The mind in the middle: A practical guide to priming and automaticity research. In H. T. Reis (Ed.), Handbook of research methods in social and personality psychology (pp. 25-285). New York: Cambridge University Press.

Bosson, J. K., Swann, W. B., \& Pennebaker, J. W. (2000). Stalking the perfect measure of implicit self-esteem: The blind men and the elephant revisited? Journal of Personality and Social Psychology, 79, 631-643.

Conner, M., \& Sparks, P. (2002). Ambivalence and attitudes. European Review of Social Psychology, 12, 37-70.

Cunningham, W. A., Preacher, K. J., \& Banaji, M. R. (2001). Implicit attitude measures: Consistency, stability, and convergent validity. Psychological Science, 12, 163-170.

Dabbs, J. M. J., Bassett, J. F., Brower, A. M., Cate, K. L., DeSantis, J. E., \& Leander, N. P. (2003, May/June). A portable version of the Go/No-Go Association Task (GNAT). Poster session presented at the 15th annual convention of the American Psychological Society, Atlanta, GA.

De Houwer, J. (2001). A structural and process analysis of the implicit association test. Journal of Experimental Social Psychology, 37, 443-451.

De Houwer, J. (2002). The implicit association test as a tool for studying dysfunctional associations in psychopathology: Strengths and limitations. Behavior Therapy and Experimental Psychiatry, 53, 115-133. 
De Houwer, J. (2003). The Extrinsic Affective Simon Task. Experimental Psychology, 50, 77-85.

De Houwer, J., Crombez, G., Koster, E. H. W., \& De Beul, N. (2004). Implicit alcohol- related cognitions in clinical samples of heavy drinkers. Journal of Behaviour Therapy and Experimental Psychiatry, 35, 275-286.

de Liver, Y., Wigboldus, D., \& van der Pligt, J. (2003). De structuur van ambivalente attitudes. In D. Wigboldus, M. Dechesne, E. Gordijn, \& E. Kluwer (Eds.), Jaarboek sociale psychologie (pp. 217-226). Delft, The Netherlands: Eburon.

Fazio, R. H. (2001). On the automatic activation of associated evaluations: An overview. Cognition \& Emotion, 15, 115-141.

Fazio, R. H., \& Olson, M. A. (2003). Implicit measures in social cognition: Their meaning and use. Annual Review of Psychology, 54, 297-327.

Fazio, R. H., Sanbonmatsu, D. M., Powell, M. C., \& Kardes, F. R. (1986). On the automatic activation of attitudes. Journal of Personality and Social Psychology, 50, 229-238.

Field, M., Mogg, K., \& Bradley, B. P. (2004). Cognitive bias and drug craving in recreational cannabis users. Drug and Alcohol Dependence, 74, 105-111.

Govan, C. L., \& Williams, K. D. (2004). Changing the affective valence of the stimulus items influences the IAT by re-defining the category labels. Journal of Experimental Social Psychology, 40, 357-365.

Greenwald, A. G., McGhee, D. E., \& Schwartz, J. L. K. (1998). Measuring individual differences in implicit cognition: The implicit association test. Journal of Personality and Social Psychology, 74, 1464-1480.

Greenwald, A. G., \& Nosek, B. A. (2001). Health of the implicit association test at age 3. Zeitschrift für Experimentelle Psychologie, 48, 85-93.

Hermans, D., De Houwer, J., \& Eelen, P. (1994). The affective priming effect: Automatic activation of evaluative information in memory. Cognition \& Emotion, 8(6), 515-533.

Hermans, D., De Houwer, J., \& Eelen, P. (2001). A time course analysis of the affective priming effect. Cognition \& Emotion, 15(2), 143-165.

Hermans, D., Spruyt, A., \& Eelen, P. (2003). Automatic affective priming of recently acquired stimulus valence: Priming at SOA 300 but not at SOA 100. Cognition \& Emotion, 17, 83-99.

Hill, A. B., \& Paynter, S. (1992). Alcohol dependence and semantic priming of alcohol related words. Personality and Individual Differences, 13, 745-750.

Hofmann, W., Gawronski, B., Gschwendner, T., Le, H., \& Schmitt, M. (2004). A meta-analysis on the correlation between the implicit association test and explicit self-report measures. Manuscript submitted for publication.

Houben, K., \& Wiers, R. W. (2004). Assessing implicit alcohol associations with the IAT: Fact or artifact? Manuscript submitted for publication. Implicit alcohol associations: Influence of target category labels and contrast categories in a unipolar IAT [Abstract]. Alcoholism: Clinical and Experimental Research, 28(5-Suppl.), 102A.

Huijding, J., de Jong, P. J., Wiers, R. W., \& Verkooijen, K. (2005). Implicit and explicit attitudes towards smoking in a smoking and a non-smoking setting. Addictive Behaviors, 30, 949-961.

Jajodia, A., \& Earleywine, M. (2003). Measuring alcohol expectancies with the implicit association test. Psychology of Addictive Behaviors, 17, 126-133.

Karpinski, A., \& Hilton, J. L. (2001). Attitudes and the implicit association test. Journal of Personality and Social Psychology, 81, 774-788. 
Klauer, K. C. (1998). Affective priming. In W. Stroebe \& M. Hewstone (Eds.), European Review of Social Psychology (Vol. 8, pp. 67-103). Chichester, UK: Wiley.

Klauer, K. C., \& Musch, J. (2003). Affective priming: Findings and theories. In J. Musch \& K. C. Klauer (Eds.), The psychology of evaluation: Affective processes in cognition and emotion (pp. 7-49). Mahwah, NJ: Lawrence Erlbaum.

Klinger, M. R., Burton, P. C., \& Pitts, G. S. (2000). Mechanisms of unconscious priming: I. Response competition, not spreading activation. Journal of Experimental Psychology, 26(2), 441-455.

Kramer, D. A., \& Goldman, M. S. (2003). Using a modified Stroop task to implicitly discern the cognitive organization of alcohol expectancies. Journal of Abnormal Psychology, 112, 171-175.

Mierke, J., \& Klauer, K. C. (2001). Implicit association measurement with the IAT: Evidence for effects of executive control processes. Zeitschrift für Experimentelle Psychologie, 48, 107-122.

Mierke, J., \& Klauer, K. C. (2003). Method-specific variance in the Implicit Association Test. Journal of Personality and Social Psychology, 85, 1180-1192.

Mitchell, J. P., Nosek, B. A., \& Banaji, M. R. (2003). Contextual variations in implicit evaluation. Journal of Experimental Psychology, 132, 455-469.

Neely, J. H. (1991). Semantic priming effects in visual word recognition: A selective review of current findings and theories. In D. Besner \& G. W. Humphreys (Eds.), Basic processes in reading: Visual word recognition (pp. 264-337). Hillsdale, NJ: Lawrence Erlbaum.

Nisbett, R. E., \& Wilson, T. D. (1977). Telling more than we can know: Verbal reports on mental processes. Psychological Review, 84, 231-259.

Nosek, B. A., \& Banaji, M. R. (2001). The Go/No-Go Association Task. Social Cognition, 19, 625-664.

Nosek, B. A., \& Hansen, J. (2004). The associations in our heads belong to us: Measuring the multifaceted attitude construct in implicit social cognition. Unpublished manuscript.

Olson, M. A., \& Fazio, R. H. (2003). Relations between implicit measures of prejudice: What are we measuring? Psychological Science, 14, 636-639.

Olson, M. A., \& Fazio, R. H. (2004). Reducing the influence of extra-personal associations on the implicit association test: Personalizing the IAT. Journal of Personality and Social Psychology, 86, 653-667.

Orford, J. (2001). Addiction as excessive appetite. Addiction, 96, 15-31.

Ostafin, B. D., Palfai, T. P., \& Wechsler, C. E. (2003). The accessibility of motivational tendencies toward alcohol: Approach, avoidance, and disinhibited drinking. Experimental \& Clinical Psychopharmacology, 11, 294-301.

Palfai, T. P. (2002). Positive outcome expectancies and smoking behavior: The role of expectancy accessibility. Cognitive Therapy and Research, 26, 317-333.

Palfai, T. P., Monti, P. M., Colby, S. M., \& Rohsenow, D. J. (1997). Effects of suppressing the urge to drink on the accessibility of alcohol outcome expectancies. Behaviour Research and Therapy, 35, 59-65.

Palfai, T. P., Monti, P. M., Ostafin, B., \& Hutchison, K. (2000). Effects of nicotine deprivation on alcohol-related information processing and drinking behavior. Journal of Abnormal Psychology, 109, 96-105.

Palfai, T. P., \& Ostafin, B. D. (2003a). Alcohol-related motivational tendencies in hazardous drinkers: Assessing implicit response tendencies using the modified-IAT. Behaviour Research and Therapy, 41, 1149-1162. 
Palfai, T. P., \& Ostafin, B. D. (2003b). The influence of alcohol on the activation of outcome expectancies: The role of evaluative expectancy activation in drinking behavior. Journal of Studies on Alcohol, 64, 111-119.

Ratcliff, R., \& McKoon, G. (1988). A retrieval theory of priming in memory. Psychological Review, 95, 385-408.

Robinson, T. E., \& Berridge, K. C. (1993). The neural basis of drug craving: An incentive-sensitization theory of addiction. Brain Research Reviews, 18, 247-291.

Robinson, T. E., \& Berridge, K. C. (2003). Addiction. Annual Review of Psychology, 54, 25-53.

Rothermund, K., \& Wentura, D. (2001). Figure-ground asymmetries in the Implicit Association Test (IAT). Zeitschrift für Experimentelle Psychologie, 48, 94-106.

Rothermund, K., \& Wentura, D. (2004). Underlying processes in the Implicit Association Test: Dissociating salience from associations. Journal of Experimental Psychology: General, 133, 139-165.

Spruyt, A., Hermans, D., De Houwer, J., \& Eelen, P. (2002). On the nature of the affective priming effect: Priming of naming responses. Social Cognition, 20, 227-256.

Stacy, A. W. (1997). Memory activation and expectancy as prospective predictors of alcohol and marijuana use. Journal of Abnormal Psychology, 106, 61-73.

Stewart, S. H., Hall, E., Wilkie, H., \& Birch, C. (2002). Affective priming of alcohol schema in coping and enhancement motivated drinkers. Cognitive Behaviour Therapy, 31, 68-80.

Swanson, J. E., Rudman, L. A., \& Greenwald, A. G. (2001). Using the implicit association test to investigate attitude-behaviour consistency for stigmatised behaviour. Cognition \& Emotion, 15, 207-230.

Teachman, B. A., Gregg, A. P., \& Woody, S. R. (2001). Implicit associations for fear-relevant stimuli among individuals with snake and spider fears. Journal of Abnormal Psychology, 110, 226-235.

Teachman, B. A., \& Woody, S. R. (2003). Automatic processing in spider phobia: Implicit fear associations over the course of treatment. Journal of Abnormal Psychology, 112, 100-109.

Weingardt, K. R., Stacy, A. W., \& Leigh, B. C. (1996). Automatic activation of alcohol concepts in response to positive outcomes of alcohol use. Alcoholism: Clinical and Experimental Research, 20, 25-30.

Wentura, D. (2000). Dissociative affective and associative priming effects in the lexical decision task: Yes versus no responses to word targets reveal evaluative judgment tendencies. Journal of Experimental Psychology: Learning, Memory, and Cognition, 26, 456-469.

Wiers, R., de Jong, P. J., Havermans, R., \& Jelicic, M. (2004). How to change implicit drug-related cognitions in prevention: A transdisciplinary integration of findings from experimental psychopathology. Substance Use \& Misuse, 39, $1625-1684$.

Wiers, R. W., Ganushchack, A., Van de Ende, N., Smulders, F. T. Y., \& de Jong, P. J. (2003, May/June). Comparing implicit alcohol associations across different RTmeasures: The Implicit Association Test (IAT) versus varieties of the Extrinsic Affective Simon Task (EAST). Paper presented at the 15th annual convention of the American Psychological Association, Atlanta, GA.

Wiers, R. W., van de Luitgaarden, J., van den Wildenberg, E., \& Smulders, F. T. Y. (2005). Challenging implicit and explicit alcohol-related cognitions in young heavy drinkers. Addiction, 100, 806-819. 
Wiers, R. W., van Woerden, N., Smulders, F. T. Y., \& de Jong, P. J. (2002). Implicit and explicit alcohol-related cognitions in heavy and light drinkers. Journal of Abnormal Psychology, 111, 648-658.

Wigboldus, D., van Knippenberg, A., Holland, R., den Hartog, G., \& Belles, S. (2001). Het verschil tussen relatieve en absolute vergelijking bij het testen van impliciete associaties. In D. A. Stapel, M. Hagedoorn, \& E. van Dijk (Eds.), Jaarboek sociale psychologie deel 1 (pp. 337-345). Delft, The Netherlands: Eburon.

Wigboldus, D. H. J., Holland, R. W., \& van Knippenberg, A. (2004). Single target implicit associations. Manuscript submitted for publication.

Wilson, T. D., Lindsey, S., \& Schooler, T. Y. (2000). A model of dual attitudes. Psychological Review, 107, 101-126.

Zack, M., Poulos, C. X., Fragopoulos, F., \& Macleod, C. M. (2003). Effects of negative and positive mood phrases on priming of alcohol words in young drinkers with high and low anxiety sensitivity. Experimental \& Clinical Psychopharmacology, 11, 176-185.

Zack, M., Toneatto, T., \& Macleod, C. M. (1999). Implicit activation of alcohol concepts by negative affective cues distinguishes between problem drinkers with high and low psychiatric distress. Journal of Abnormal Psychology, 108, 518-531. 